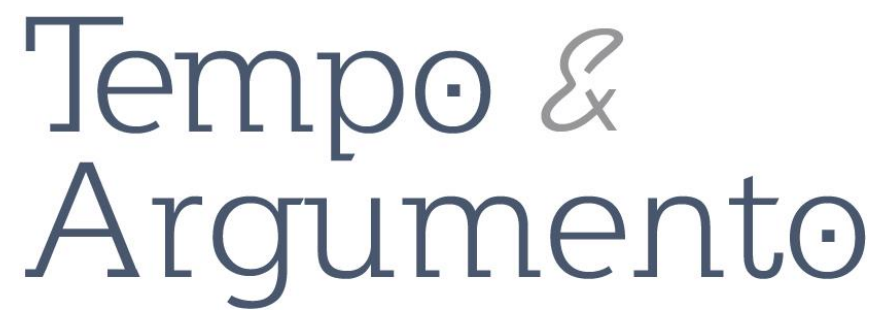

\title{
Consultas comunitarias en Argentina: respuestas participativas frente a mega-proyectos
}

\begin{abstract}
Resumen
Este trabajo analiza las consultas comunitarias resultantes de conflictos socioambientales en Argentina, enmarcándolas en un boom de estas experiencias participativas en Latinoamérica. El objetivo es explicar las motivaciones que impulsan la realización de consultas comunitarias, y cuáles son sus efectos para las sociedades que participan y en la institucionalidad ambiental. Nos basamos en 13 años de investigaciones sobre conflictividad socioambiental en Argentina, incluyendo trabajo de campo en diferentes localidades y análisis de diversas fuentes documentales. Analizamos en profundidad el caso de la consulta por minería en Loncopué, en 2012, la segunda consulta realizada en Argentina por este tema.
\end{abstract}

Palabras clave: Conflictos Socioambientales. Consulta Comunitaria. Argentina. Participación. Loncopué.

\author{
Lucrecia Soledad Wagner \\ Doctora en Ciencias Sociales y Humanas. \\ Investigadora del CONICET. Docente del \\ Doctorado en Ciencias Sociales de la \\ Universidad Nacional de Cuyo. \\ Mendoza - ARGENTINA \\ lucrewagner@gmail.com \\ orcid.org/0000-0002-0848-5255
}

\section{Para citar este artículo:}

WAGNER, Lucrecia Soledad. Consultas comunitarias en Argentina: respuestas participativas frente a mega-proyectos. Tempo e Argumento, Florianópolis, v. 11, n. 28, p. 181 - 211, set./dez. 2019.

\section{DOI: 10.5965/2175180311282019181}

http://dx.doi.org/10.5965/2175180311282019181 
Community consultations in Argentina: participatory responses to megaprojects

\begin{abstract}
This paper analyzes community consultations resulting from socio-environmental conflicts in Argentina, framing them within a Latin American boom in these participatory experiences. The objective is to explain the motivations that drive the realization of community consultations, and their effects for the societies that participate and in the environmental institutionality. We based on 13 years of research on socioenvironmental conflicts in Argentina, including fieldwork in different localities and analysis of diverse documentary sources. We analyzed in depth the case of the consultation about a metaliferous mining project in Loncopué, in 2012, the second consultation on this subject carried out in Argentina.
\end{abstract}

Keywords: Socio-Environmental Conflicts. Community Consultation. Argentina.

Participation. Loncopué.

\section{Consultas comunitárias na Argentina: respostas participativas frente a mega-projetos}

\begin{abstract}
Resumo
Este artigo analisa as consultas comunitárias resultantes de conflitos socioambientais na Argentina, enquadrando-as num boom dessas experiências participativas na América Latina. O objetivo é explicar as motivações que impulsionam a realização de consultas comunitárias, e quais são seus efeitos para as sociedades participantes e as instituições ambientais. Nossos dados estão baseiados em 13 anos de pesquisas sobre conflitos socioambientais na Argentina, incluindo trabalho de campo em diferentes localidades e análise de várias fontes documentais. Analisamos em profundidade o caso da consulta pelo projeto de mineração em Loncopué, em 2012, a segunda consulta sobre este tema na Argentina.
\end{abstract}

Palavras-chave: Conflitos Socioambientais. Consulta Comunitária. Argentina. Participação. Loncopué.

\section{Introducción}

En este trabajo nos interesa dar cuenta de un proceso que viene acrecentándose en las últimas décadas en América Latina: el boom de consultas comunitarias, resultantes de conflictos socioambientales donde empresas y gobiernos han intentado imponer su decisión de llevar adelante una actividad que las comunidades locales consideraron perjudicial por sus impactos ambientales negativos, impulsando su rechazo.

Estos procesos no son exclusivos de América Latina, destacándose que existe un movimiento global de Justicia Ambiental (MARTíNEZ; TEMPER; DEL BENE; SCHEIDEL, 2016), en el cual, América Latina ocupa un creciente protagonismo. Durante las últimas 

(ALIMONDA, 2006, 2011; SVAMPA, 2016).

Con antecedentes en las últimas décadas del siglo Xx, pero acentuándose a inicios del siglo XXI, los conflictos ambientales en América Latina que más se han destacado son aquellos que se generaron por la instalación de proyectos mineros, proyectos hidroeléctricos, explotación de petróleo y gas, monocultivos, industrias contaminantes y obras de infraestructura, entre otras actividades problemáticas. Los conflictos ambientales se han constituido como experiencias "productivas", en el sentido de lo que Gabriela Merlinsky (2013) denomina “productividad institucional de los conflictos", que se evidenciaría cuando el conflicto habilita dispositivos de participación social en la formulación y/o implementación de políticas públicas.

Las consultas comunitarias son procesos de votación directa de la población local, donde cada habitante elige entre el «SI» O el «NO» a una actividad cuestionada. Los gobiernos locales a veces suelen validarlas, pero en muchos casos se realizan sin su consentimiento. Son impulsadas por la propia población que quiere plasmar su decisión en una votación, y se convierten en un mecanismo diferente y complementario a la consulta previa, libre e informada planteada para los pueblos indígenas y tribales en el Convenio 169 de la Organización Internacional del Trabajo (OIT). En el caso de las consultas comunitarias, los votantes pueden ser, o no, de comunidades indígenas y/o tribales, y su realización no está formalizada en un convenio, ley o reglamentación, aunque, como veremos a continuación, existen casos en los que se han utilizado formas existentes en la legislación para llevarlas adelante, como en Loncopué, Argentina.

La particularidad de estas consultas es que no están fomentadas por los gobiernos nacionales como parte de los procedimientos oficiales para consultar a las comunidades, sino que están promovidas por movimientos de justicia ambiental, generalmente con el soporte de los gobiernos locales (WALTER; URKIDI, 2015, p. 48). 
Estos procesos participativos han recibido diversos nombres en la bibliografía existente: Consultas comunitarias y vecinales (WALTER; URKIDI, 2015), Consultas populares (DIETZ, 2018), y Mecanismos de Democracia Directa (MDD) (HINCAPIÉ, 2017), incluyendo en este último caso la Consulta Previa y las Consultas Populares locales. En este trabajo se ha optado por la denominación utilizada por Mariana Walter y Leire Urkidi (2015), consultas comunitarias, considerando que el término comunidad resulta el más pertinente para definir los procesos sociales que se generaron en torno a la conflictividad ambiental, en especial en Argentina. Una noción de comunidad que se asemeja a la definición de Benedict Anderson (1993) de Comunidades Imaginadas, "que se conciben siempre como un compañerismo profundo, horizontal, una fraternidad" (ANDERSON, 1993, p. 25). Si bien Anderson desarrolló este concepto para definir a las Naciones, en nuestro caso lo utilizamos para definir procesos de organización social que mayoritariamente se autodenominaron en Argentina Asambleas de Vecinos Autoconvocados, una de cuyas principales características es la horizontalidad en la toma de decisiones, entre sus integrantes. Estas asambleas socioambientales son las que impulsaron las consultas comunitarias por problemáticas socioambientales que acontecieron en el país.

Las consultas comunitarias son una de las máximas expresiones de esta productividad institucional del conflicto, si consideramos a las comunidades como agentes fundamentales de esta renovación institucional, y a la participación social como instrumento de estos agentes. Aun cuando muchas de ellas han sido de carácter no vinculante, es decir, el resultado no implica directamente la prohibición o aprobación del proyecto, el gobierno local o regional ha reaccionado ante los resultados de las consultas, y los proyectos en cuestión no se han llevado adelante. Las consultas más investigadas han sido aquellas realizadas por proyectos de minería metalífera. Sobre estas consultas, Mariana Walter y Leire Urkidi (2015) destacan que, en todos los casos el resultado ha sido una gran oposición a los proyectos mineros. Para el periodo 2002-2012 las autoras identificaron 68 consultas sobre minería metálica en cinco países latinoamericanos: Perú (2002, 2007, 2008, 2009 y 2012), Argentina (2003, 2012), Ecuador (2011), Colombia (2009) y Guatemala (57 consultas municipales desde Sipacapa en 2005 a Mataquescuintla en 2012). 
La consulta constituye una institución híbrida ${ }^{1}$ que reivindica el derecho a participar de las poblaciones afectadas por proyectos que ponen en riesgo sus tierras y modos de vida. Las autoras destacan la importancia de la formación de redes que impulsaron la difusión de las consultas, algunas de las cuales nacieron de las primeras experiencias de consultas sobre minería: Tambogrande, Esquel y Sipacapa, los tres "fueron conflictos mineros relevantes tanto a escala nacional como transnacional, marcando un antes y un después en los procesos de consulta sobre minería en Latinoamérica y en sus propios países" (WALTER; URKIDI, 2015, p. 50). Por otro lado, en relación a la posición del gobierno, las consultas se han llevado adelante gracias a la alianza entre los movimientos sociales y los gobiernos locales, ya sea que éstos estuvieron desde el inicio a favor de la consulta o cambiaron su posición a partir del conflicto, y que la legitimidad de estas consultas es causa y consecuencia de estas “alianzas híbridas” (WALTER; URKIDI, 2015, p. 51).

También sobre consultas por minería en América Latina, en los últimos años, el trabajo de Kristina Dietz (2018) concluye en que estas consultas movilizan a una gran parte de la población, influyen en la agenda política y las reglas institucionales, y abren nuevos espacios de debate y participación democrática. Carla Noever y Kristina Dietz (2017) relevaron en diciembre de 2017 la realización de 95 consultas populares por minería en América Latina, en seis países: a los países relevados por Walter y Urkidi (2015), se sumó El Salvador, donde entre 2014 y 2017 se llevaron adelante cinco consultas. Dietz (2018) destaca el alto potencial de movilización que generan las consultas populares en conflictos sobre minería, como instrumento de democracia directa. El caso paradigmático ha sido el de Colombia, donde se han llevado a cabo siete consultas, cinco de ellas durante $2017 .^{2}$

Hay controversia respecto a la validez, legalidad y legitimidad de este mecanismo de participación tanto a nivel jurídico como político, sin embargo, las consultas realizadas empiezan a tener repercusiones políticas, ya que en algunos casos ayudaron a que los proyectos mineros se detuvieran temporalmente, tuvieran que ser modificados en su diseño o, inclusive, lograron pararlos (DIETZ, 2018, p. 96).

\footnotetext{
${ }^{1}$ Combinación de instituciones formales e informales, modernas y tradicionales adaptadas, en cualquier caso, al contexto local (WALTER; URKIDI, 2015, p. 51).

² Carmen del Darién (2009), Piedras (2013) y Cabrera, Cajamarca, Pijao, Arbeláez y Jesús María (2017) (DIETZ, 2018).
} 
Dietz coincide con Walter y Urkidi (2015), al resaltar que gobiernos nacionales y empresas presionan por deslegitimar estos procesos participativos, aumentando el conflicto entre éstos y los gobiernos y actores locales. En la misma línea, Sandra Hincapié (2017) destaca que los mecanismos de democracia directa, activados en medio de conflictos socioambientales en América Latina, se han convertido en:

un importante recurso de movilización y acción colectiva desde abajo, mientras los gobiernos centrales desde arriba han tratado de limitar su alcance o prohibir su implementación, en la medida que pone en el debate público las consecuencias del modelo económico orientado a la apropiación extractivista de los recursos naturales (HINCAPIÉ, 2017, p. 1).

En este marco contextual, analizaremos las experiencias de consultas comunitarias en Argentina, a fin de destacar los puntos en común y sus particularidades, en relación a las experiencias similares sucedidas en América Latina.

\section{Argentina: participación, democracia e institucionalidad ambiental}

Argentina es un país federal, y en la reforma constitucional de 1994 estableció, en su artículo 124, que "corresponde a las provincias el dominio originario de los recursos naturales existentes en su territorio". Ello implica que toda actividad que explotará recursos naturales necesita un permiso ambiental que es otorgado por el gobierno provincial. Esto ha generado que las provincias se transformen en los territorios por excelencia de las disputas, y los gobiernos provinciales en el foco de las diversas presiones de los actores en conflicto. Por su parte, la legislación ambiental nacional se constituye como una base de presupuestos mínimos, que las provincias deben respetar, pero sobre la cual también pueden ampliar su propia legislación. El ejemplo más evidente ha sido la legislación relativa a la minería a gran escala, ya que siete provincias argentinas poseen legislación restrictiva a la actividad, mientras que otras tienen gobiernos que favorecen la instalación de la actividad, decisión que es acompañada con instituciones ambientales más débiles y con escaso poder de policía ambiental sobre las actividades extractivas que se desarrollan. Las legislaciones restrictivas fueron resultado de conflictos ambientales provinciales, en los cuales parte de su ciudadanía demandó, exitosamente, la ampliación de la preservación ambiental. Es así que en los últimos años se observa un 
nuevas legislaciones que en algunos casos crean y recrean espacios de participación en materia ambiental.

Diferentes análisis (DI PAOLA; NAPOLI, 2007; MERLINSKY, 2013) destacan que los precedentes judiciales en la materia se han incrementado notablemente en las últimas décadas, mayoritariamente impulsados por los propios vecinos afectados. Este proceso no podría explicarse sin lo que Abers, Gutiérrez, Isuani y von Bülow (2013) han caracterizado como el "encuentro" entre el ambientalismo social y el ambientalismo estatal, "haciéndose visible el impacto del primero sobre el segundo a partir de una serie de conflictos ambientales" (ABERS; GUTIÉRREZ; ISUANI; VON BÜLOW, 2013, p. 17). Los autores mencionados destacan la fertilidad de los nuevos recursos legales a la hora de plantear demandas ambientales, en mano de este "nuevo ambientalismo social” cuyo impacto en la política ambiental puede apreciarse tanto en el plano normativo como en el organizacional. Ricardo Gutiérrez (2015) ha destacado tres modos de contienda ambiental que convergen en la actualización de los derechos ambientales: el litigio judicial, la protesta social y la controversia experta. El autor argumenta que los distintos modos de acción contenciosa son tan importantes como los mecanismos de participación institucionalizada (consejos, comités, audiencias públicas) en la apropiación y puesta en vigencia de los derechos ambientales.

La participación institucionalizada en la formación de políticas ambientales es, en Argentina, muy imperceptible, mientras que la participación de ciudadanos y organizaciones en protestas sociales y litigios judiciales ha sido muy efectiva en colocar las cuestiones ambientales en primera plana de la agenda pública, en aumentar la importancia de los derechos ambientales introducidos con la reforma de $1994 \mathrm{y}$, a veces, incluso en cambiar o dirigir el curso de decisiones estatales (GUTIÉRREZ, 2015, p. 19).

Así, Gutiérrez (2015), destaca que las organizaciones ambientales otorgaron a los derechos ambientales una vigencia y legitimidad que parecían estar adormecidas antes de las primeras protestas que tuvieron lugar a principios del nuevo siglo. 
Tomando este marco analítico, en este trabajo indagamos, además, en la centralidad de la presencia de actores claves como portadores de un "acervo vivencial". Entendemos como tal a un conocimiento común, proveniente de la experiencia de un colectivo social, el cual, gracias a determinados individuos -y en este caso combinándose con su expertise legal-, se transmite entre comunidades, reeditándose mediante la creación de estrategias en un nuevo escenario de conflicto. Gabriela Delamata identifica la constitución de una "comunidad legal ambientalista «joven»", como uno de los antecedentes que ha favorecido la acción social de tipo legal.

Con ello nos referimos tanto a la presencia de magistrados, en distintas instancias y jurisdicciones, que vienen realizando una lectura garantista del derecho al medio ambiente, sentando precedentes jurisprudenciales en una materia «joven», en razón de su incorporación constitucional reciente, y al activismo de abogados, locales o con presencia nacional, que, desde un paradigma similar y con sentido social transformador, acompañan los reclamos y dan pelea en el terreno legal, asesorando a las organizaciones y juridificando las demandas (DELAMATA, 2013, p. 87).

\section{Experiencias y normativas en Argentina}

Las experiencias argentinas de consultas comunitarias han sido impulsadas por asambleas socioambientales, y se han llevado adelante bajo diferentes formas, ya que éstas varían según la normativa nacional, provincial y/o municipal. La primera consulta comunitaria en Argentina por un proyecto minero, y segunda en Latinoamérica, fue Esquel, en la provincia de Chubut, en 2003, y se trató de una consulta popular no vinculante. Posteriormente, la segunda consulta por minería metalífera fue en Loncopué, Neuquén, en 2012, bajo la forma de referéndum.

A nivel nacional, el artículo $40^{3}$ de la Constitución Nacional introduce la figura de consulta popular. La Ley 25.432 (ARGENTINA, 2001), modificada por la Ley 26.774 (ARGENTINA, 2012) establece las condiciones de la Consulta Popular Vinculante y No

\footnotetext{
${ }^{3}$ Artículo 40 (Constitución Nacional). El Congreso, por iniciativa de la Cámara de Diputados, podrá someter a consulta popular un proyecto de ley. La ley de convocatoria no podrá ser vetada. El voto afirmativo del proyecto por el pueblo de la Nación lo convertirá en ley y su promulgación será automática. El Congreso o el presidente de la Nación, dentro de sus respectivas competencias, podrán convocar a consulta popular no vinculante. En este caso el voto no será obligatorio. El Congreso, con el voto de la mayoría absoluta de la totalidad de los miembros de cada Cámara, reglamentará las materias, procedimientos y oportunidad de la consulta popular.
} 
Vinculante. La consulta popular vinculante se realiza para someter a votación proyectos de ley. La votación es obligatoria y el resultado válido cuando vote no menos del treinta y cinco por ciento (35\%) de los electores inscriptos en el padrón electoral nacional. Si la mayoría de los votos es afirmativa, el proyecto se convierte automáticamente en ley. Por su parte, la consulta popular no vinculante se realiza para someter asuntos de interés general para la Nación. El voto del electorado no es obligatorio. Si el proyecto de ley obtiene voto afirmativo de la mayoría absoluta de votos válidos emitidos, deberá ser tratado por el Congreso de la Nación.

En línea con estas leyes, el Plebiscito es de carácter consultivo, no definitivo y tiene por objeto conocer la opinión de los habitantes sobre un determinado tema. Se trata de una consulta popular no vinculante, ya que el voto no es obligatorio y la decisión no implica directamente una obligación que se plasme en una ley o política pública. Por su parte, en la Consulta popular vinculante (asimilable a Referéndum) los ciudadanos, mediante el voto, aprueban o desaprueban en forma definitiva algún proyecto de ley presentado por el Poder Legislativo, el Ejecutivo o por Iniciativa Popular. Así, el voto afirmativo de los ciudadanos lo convierte en ley en forma automática.

A partir de estas consideraciones, en este trabajo indagamos en lo que Patrice Mele ha denominado “dimensiones espaciales y territoriales del derecho” (Melé, 2007).

\section{Antecedentes de consultas comunitarias: represas sometidas a la decisión de la población}

En Argentina, desde la década de 1980 emergen conflictos ambientales caracterizados por la movilización social organizada en ciertas localidades del país, en rechazo a proyectos considerados contaminantes. Varios de ellos sucedieron en la Patagonia y fueron relatados por sus propios protagonistas en el libro "La Patagonia de Pie" (CHIAPPE, 2005). Pero también se ampliaban los ecos de problemáticas urbanas, de contaminación del agua, industrias y basurales, con alto impacto en las condiciones de vida de la población, sumado a que, en el noreste del país, la apropiación del territorio por parte de las empresas madereras se sumaba al impacto de los proyectos hidroeléctricos. 
La primera consulta comunitaria llevada adelante en Argentina por un conflicto ambiental fue la que se realizó por el proyecto hidroeléctrico Corpus Christi. Esta consulta se realizó ocho años antes que el plebiscito de Esquel, si bien este último tuvo más trascendencia debido a que fue la segunda consulta por un proyecto minero metalífero en América Latina. La comunidad de Esquel rechazó un proyecto de oro en la provincia de Chubut, en 2003, un año después de la consulta de Tambogrande, en Perú.

En 1996, la población de la provincia de Misiones, noreste de Argentina, rechazó el proyecto hidroeléctrico binacional Corpus Christi, localizado sobre el río Paraná, entre Argentina y Paraguay. Planificado desde la década de 1960, se evaluaban tres localizaciones posibles (Pindoí, Itacuá e Itacurubí). Corpus se planificaba en el tramo del río que se encuentra entre la represa de Itaipú (aguas arriba) y la de Yacyretá (aguas abajo), lo cual implicaba además impactos acumulativos con las represas ya existentes.

El rechazo social al proyecto hidroeléctrico Corpus Christi llevó a que el gobierno de la provincia de Misiones sancionara una ley, que incluyó la participación social en la decisión sobre la instalación del proyecto. La ley 3220 de 1995 estableció:

el régimen de consulta popular para que la población de la Provincia se expida, mediante plebiscito obligatorio y vinculante, aceptando o rechazando la construcción de la represa Binacional denominada Corpus Christi, cualquiera fuere el lugar de su emplazamiento en territorio misionero, sobre el Río Paraná. (MISIONES, 1995).

Los comicios que se llevarían adelante estaban enmarcados en la aplicación de las normas electorales vigentes en el Código Electoral Provincial. Así, la consulta se realizó con la forma de plebiscito vinculante, y tuvo escala provincial, una de las grandes diferencias en relación a las posteriores consultas que se realizarían por proyectos mineros, de escala local. La consulta en Misiones fue impulsada por grupos ambientalistas, partidos políticos y diversas organizaciones sociales, junto a referentes como el obispo Joaquín Piña y el Premio Nobel de la Paz, Adolfo Pérez Esquivel. La fecha de realización de la consulta, que se realizaría en enero de 1996, fue prorrogada mediante la Ley 3263, a pedido del entonces gobernador de Misiones, quien argumentó la necesidad de que la población pudiera acceder a mayor información, de que hubiese 
ambientalistas comenzaron una campaña de difusión de información, a través de folletos, pasacalles y afiches, hechos con el aporte de vecinos y comercios. Las Iglesias y partidos políticos plasmaron en diferentes eventos su posicionamiento por el NO. En octubre de 1995, movimientos ambientalistas, hoy nucleados en la Red de Asociación Ecologista (RAE), junto a iglesias, organizaron un acto en la ciudad de Corpus, al cual sus integrantes llegaron en lancha desde diferentes puntos de la provincia por el río Paraná, representando a clubes de pesca, partidos políticos, gremios, entre otros, con las figuras centrales del Obispo Piña y de Adolfo Pérez Esquivel (BENÍTEZ; HERTTER, 2012).

El día del plebiscito, el $88,63 \%$ de los votantes se manifestó por el $\mathrm{NO}$ al proyecto (62,85\% del padrón electoral). Posteriormente a su realización, la Ley 3294 (MISIONES, 1996) ratificó y otorgó fuerza de ley a la Resolución $n^{\circ} 420$ del Tribunal Electoral de la Provincia de Misiones, del 24 de abril de $1996^{4}$, referida al plebiscito. En esta ley se establece que

Toda intervención de los poderes del Estado Provincial, en relación al tema plebiscitado, que se ejecute en el cumplimiento de las atribuciones constitucionales deberá hacerse con sujeción a la decisión de la ciudadanía expresada en esta consulta (MISIONES, 1996, p. 1, artículo 3 ).

A inicios de la década de 2000 se reactivó el proyecto, planteando la convocatoria de un nuevo plebiscito. La fundamentación de los gobernantes provinciales fue que el proyecto había sido modificado, y que la opción elegida, Pindoí, afectaba menos hectáreas y minimizaba los impactos negativos. Entre éstos, se destaca el desplazamiento de personas, la pérdida de infraestructura y tierras productivas, y el aumento de vectores de enfermedades. Las organizaciones sociales y ambientales que se opusieron al proyecto aludían reiteradamente a la experiencia ya vivida con la represa Yacyretá, argumentando además que Misiones recibía los impactos negativos, a la vez que pagaba cara su energía, aun cuando ésta se generaba en su territorio.

\footnotetext{
${ }^{4}$ Expediente $\mathrm{N}^{\circ}$ 654-bis 1-95.
} 
Ante estos reintentos de construir el proyecto hidroeléctrico, las organizaciones que llevaron adelante la consulta continúan trabajando para impulsar el tratamiento legislativo de una ley que declare a Misiones “libre de represas". En 2011 el mecanismo de consulta, explícitamente asociado a la decisión sobre proyectos hidroeléctricos, fue incluido en la legislación provincial: la Ley IV-Nº 56 (MISIONES, 2011) estableció que “Todo emprendimiento hidroeléctrico que requiera o utilice los recursos naturales hídricos de la Provincia, debe contar con la participación del pueblo de Misiones e intervención activa del Estado provincial" (MISIONES, 2011, P. 1, artículo 2). En su artículo 6, determina que, para la realización de emprendimientos hidroeléctricos y represas, se requiere la participación previa del pueblo de la Provincia de Misiones, mediante plebiscito obligatorio, vinculante e irrenunciable, "y cuyos efectos duran mientras las condiciones particulares e históricas que dieron motivo a la decisión del plebiscito perduren" (MISIONES, 2011, p. 2, artículo 6).

En este contexto, se fue gestando el movimiento Mesa Provincial No a las Represas:

nuclea 46 organizaciones. Indígenas, campesinos, organizaciones sindicales y de derechos humanos, iglesias (evangélica, luterana y católica). Un amplio abanico y diversidad de posicionamientos políticos, con la coincidencia de rechazar las represas. Estas organizaciones denuncian los efectos sociales (masivos desalojos forzosos), sanitarios (enfermedades), ambientales (inundación de extensas superficies y pérdida de biodiversidad) y el "mal desarrollo" (sacrificar territorios y producir energía de forma no sustentable) (ARANDA, 2014).

Esta Mesa exige el cumplimiento de la Ley IV-56. Ante la negativa del gobierno de ponerla en práctica, decidió llevar adelante una consulta popular, sobre la instalación de proyectos hidroeléctricos en Misiones, a lo cual los misioneros nuevamente dijeron NO (en un 96 \%), en una votación auto-gestionada y de carácter no vinculante. Esta consulta, como en otras experiencias latinoamericanas, contó con fiscalización de ONG y veedores nacionales e internacionales. contó con la presencia de veedores externos, como integrantes de las Madres de Plaza de Mayo, investigadores del Consejo Nacional de Investigaciones Científicas y Técnicas (CONICET), organizaciones ambientales (Fundación Mbiguá, Vida Silvestre), asambleas ciudadanas y periodistas nacionales e internacionales, entre otros. La Mesa impulsa el tratamiento legislativo del proyecto de "Ley de Ríos 

transmisoras de experiencias y difusión de las problemáticas a las que se enfrentan los movimientos sociales (BENÍTEZ; HERTTER, 2012; GÓMEZ et. al., 2014). En Argentina, parte de los proyectos hidroeléctricos que han generado resistencias sociales se desarrollan o están proyectados sobre ríos compartidos con otros países, lo que ha favorecido la presencia de las organizaciones que se oponen a estas represas en eventos internacionales de los afectados por represas. Sumado a ello, la creciente conflictividad socioambiental ha llevado a la necesidad, por parte de las organizaciones ambientales y movimientos sociales implicados, de propiciar encuentros y coordinación de acciones, como la Unión de Asambleas Ciudadanas (UAC), donde la mayor parte de los grupos (y redes) que la conforman están abocados a luchar en contra de proyectos megamineros y de agronegocios, de desalojos por el avance de la frontera agrícola y contra los impactos de industrias contaminantes, entre otras problemáticas socioambientales. Si bien en Argentina no hay un frente nacional de resistencia a las represas, como existen en otros países, los grupos de afectados se han vinculado con redes a nivel latinoamericano y nacional, participando de los encuentros de la UAC. Esto ha favorecido que ciertos conflictos (Yacyretá, Corpus Christi, Garabí, y algunos de la región patagónica), hayan tenido mayor trascendencia mediática y continuidad en el tiempo.

\section{Consultas por proyectos mineros metalíferos: el No a la Mina de Esquel}

La consulta realizada en la localidad de Esquel, en Chubut, Patagonia argentina, fue la más difundida de las consultas realizadas en Argentina. Esquel es parte, como destacan Mariana Walter y Leire Urkidi (2015), de las consultas pioneras por proyectos mineros en Latinoamérica. Los vecinos Autoconvocados por el No a la Mina de Esquel, tomaron la idea de realizar una consulta de la experiencia que un año antes se había llevado adelante en Tambogrande, Perú, la primera consulta latinoamericana. Como ya se

\footnotetext{
${ }^{5}$ Acceso al texto completo en: http://mesanoalasrepresas.org.ar/proyecto-ley-de-rios-libres/
} 

el país: el nacimiento del No a la Mina.

La relación entre Esquel y Tambogrande proviene del conocimiento de la lucha de Tambogrande por los vecinos de Esquel a través de internet. También hay vínculos tempranos de Esquel con Mining Policy Center (actualmente Earthworks) la organización que apoyó la consulta en Tambogrande y, junto a Greenpeace, financió la visita a Esquel del hidrogeólogo Robert Moran, que también había sido convocado en Tambogrande (WALTER, 2014).

Diversos sectores de la localidad de Esquel se movilizaron manifestando su oposición a la instalación de un proyecto de minería metalífera a cielo abierto, perteneciente a la compañía Meridian Gold. En noviembre de 2001, la Minera El Desquite S.A. (MED) había presentado el estudio de prefactibilidad realizado por la Universidad Nacional de la Patagonia San Juan Bosco (UNPSJB). A principios de 2002, MED fue comprada por Meridian Gold Inc. (MG) que, como requisito para comenzar la explotación, debía elaborar un Informe de Impacto Ambiental y defenderlo en Audiencia Pública. Dicho informe se presentó en octubre de 2002, momento en el cual comenzaron las primeras reacciones populares, estando la audiencia del proyecto prevista para el 4 de diciembre del mismo año (WEINSTOCK, 2012).

Estas reacciones de algunos sectores de la sociedad esquelense estaban basadas en la inquietud en torno a la contaminación que podría ocasionar el método de separación del oro y la plata de la roca con la utilización de cianuro, lo que impactaría en otras actividades desarrolladas existentes en el lugar -turismo, agricultura orgánica, ganadería ovina y bovina, acuicultura de truchas, entre otras-. Los pobladores que desconfiaban de esta actividad, que era postulada por el sector gubernamental como una alternativa de desarrollo para la localidad, comenzaron a reunirse hasta decidir conformar una Asamblea de Vecinos Autoconvocados. Estas reuniones derivaron en movilizaciones masivas, también organizadas en otras localidades de la provincia de Chubut que se plegaron al rechazo del proyecto minero, logrando la postergación de la audiencia pública 
gente como la que ayer coreó Sí a la vida, no a la mina” (GUAJARDO, 2002). Posteriormente, la continuidad de la movilización ejerció una presión que obligó al gobierno a llevar adelante un plebiscito, realizado en marzo de 2003, que tuvo como resultado un $81 \%$ de votos por el $\mathrm{NO}$ a la Mina. Este plebiscito (de carácter no vinculante) fue el primero de su tipo llevado adelante en el país desde la reforma constitucional de 1994 (SCHIAFFINI, 2003).

La notoriedad de Esquel es explicada por una conjunción de factores: su devenir meteórico, los intereses económicos en juego, la notoriedad que alcanzó y la diversidad de actores involucrados. Mereció la atención de la prensa internacional (MOORE, 2013) y generó formas de aprendizaje, organización y acción que fueron replicadas en otros lugares del país donde compañías extranjeras propusieron proyectos extractivos similares (CLAPS; COLAO, 2005). Entre los aspectos en los que Esquel se destaca como movimiento referente de los que surgieron con posterioridad en muchas localidades del país, se encuentra la conformación de la página web ${ }^{6}$ de la asamblea de Esquel, actualmente fuente de información actualizada sobre los conflictos mineros del país y del mundo.

Además, el conflicto de Esquel se desarrolló en un momento histórico de gran descrédito de los sectores político-partidarios y los gobiernos en sus diferentes escalas. Huelgas generales, manifestaciones, cortes de rutas y calles, piquetes y escraches en casi todo el país, se venían multiplicando desde mediados de la década de 1990. En noviembre de 2001 comenzaron a producirse saqueos en diferentes ciudades argentinas, siendo emblemático el caso de Rosario, en la provincia de Santa Fe. Finalmente, el 19 y 20 de diciembre de 2001, confluyeron diversos hechos: saqueos, cacerolazos, represión y movilización popular, terminaron con el abandono del país por parte del entonces presidente, Fernando De la Rúa, en un helicóptero desde la propia casa de gobierno. La crisis social y económica se cristalizó en una crisis política que condujo a la sucesión de

\footnotetext{
${ }^{6}$ En línea: http://www.noalamina.org/.
} 

generalizada dio lugar a acciones populares callejeras y a nuevos ethos militantes por fuera del Estado, así como también generó un corrimiento y ampliación de las fronteras del conflicto social, luego de diez años de políticas neoliberales que habían socavado y transformado enormemente las estructuras sociales. Allí van a emerger las asambleas de vecinos Autoconvocados, cuya organización inspirará a aquellas que, unos años después, se formarían para llevar adelante demandas de carácter socioambiental.

En relación a ello, Mariana Walter destaca, para el caso de Esquel,

Es ilustrativo que en momentos del plebiscito se incorporara en las actividades y marchas vecinales la consigna que se vayan todos, un lema asociado a la intensa movilización ciudadana que en la crisis nacional del 2001condensó la pérdida de confianza y credibilidad de la clase política" (WALTER, 2008, p. 22).

La asamblea de Esquel impulsó tres ordenanzas (legislación municipal), que fueron aprobadas por el Concejo Deliberante de Esquel (poder legislativo municipal). Una prohibía el uso de cianuro en la meseta de Esquel, la cual fue revocada por el intendente. Otra derogaba la adhesión Municipal a la ley 24.196 de Inversiones Mineras y a la ley 3866 de adhesión provincial por "atentar contra el perfil turístico y los intereses de la comunidad local” (Walter, 2008, p. 23). La tercera, convocaba a un referéndum popular sobre el emprendimiento minero, pero éste era no vinculante (WALTER, 2008). Mariana Walter afirma que esta consulta marcó un cambio en la dinámica del conflicto, ya que colocó en el centro del escenario político el nivel local, polarizó a los sectores a favor y en contra del proyecto y desvió el centro de atención, desde las instituciones y el Gobierno, a los 20.000 esquelenses que debían votar.

\footnotetext{
7 Ellos fueron: Fernando de la Rúa, Ramón Puerta, Adolfo Rodríguez Saa, Eduardo Camaño y Eduardo Duhalde. Este último asume el 2 de enero de 2002 y se mantiene en el poder ejecutivo hasta las elecciones presidenciales del año 2003, en las que es electo Néstor Kirchner.
} 
El 23 de marzo tiene lugar entonces el plebiscito, con la participación del $75 \%$ de los 20.000 votantes convocados. El resultado es de un $81 \%$ por el No a la Mina. Días más tarde la empresa y gobierno provincial anuncian la interrupción de los trabajos, el Concejo Deliberante local prohíbe la minería con lixiviación de cianuro en Esquel y se aprueba en la Legislatura Provincial una prohibición a la minería a cielo abierto con lixiviación de cianuro (WALTER 2008, p. 24).

La ley provincial restrictiva de la actividad minera en Chubut, sería la primera de nueve leyes similares que se sancionaron en diferentes provincias argentinas en los años consecutivos (de 2005 a 2011), dos de las cuales fueron posteriormente vetadas.

\section{Por el SI a la ordenanza: el Referéndum de Loncopué}

Loncopué es una localidad del noroeste de la provincia de Neuquén, a unos 300 kilómetros aproximadamente de la capital provincial. En el departamento homónimo, del cual la ciudad de Loncopué es cabecera, viven alrededor de 7.000 habitantes (6.925, según INDEC, 2010), de los cuales 5.010 viven en la meseta municipal. Allí conviven pobladores que llegaron desde otros lugares del país en las últimas décadas, eligiendo Loncopué como lugar de vida y/o por motivos laborales, y los “nacidos y criados", tanto

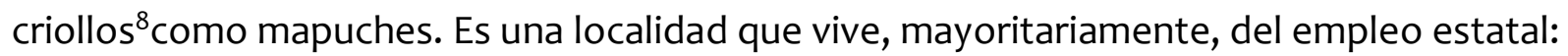
el complejo de Termas de Copahue-Cavihaue, personal del Municipio, policía, docentes. No es un poblado turístico en sí mismo, pero está camino a dos lugares que sí lo son: Copahue y Caviahue, al noroeste de Loncopué, con sus paisajes de araucarias y lagunas, y el volcán Copahue, cuya actividad ha dado lugar al Complejo Termal de Copahue. Además, se encuentra rodeado de estancias y campos privados. La zona se destaca por su producción ganadera, que varía entre grandes estancias con un importante número de cabezas de ganado, y crianceros que desarrollan sus actividades ganaderas basados en la trashumancia.

La originalidad y trascendencia del conflicto de Loncopué radica en que esta lucha surgió de la unión local de sectores campesinos (crianceros), indígenas (comunidad mapuche Mellao Morales), asambleas de vecinos autoconvocados (de Loncopué, AVAL, y

\footnotetext{
${ }^{8}$ En la zona se denomina criollo a aquel que ha nacido en el territorio pero no forma parte de una comunidad indígena. Si bien sus características socioeconómicas pueden ser similares, no lo son las identitarias. Por ello existen "crianceros criollos" y "crianceros mapuches".
} 
bien el proyecto minero que mayor rechazo generó, se desarrollaría con capitales chinos (empresa MCC), la presencia de la Corporación Minera del Neuquén (CORMINE), una empresa del Estado provincial dedicada al desarrollo de la minería junto a inversores privados, como dueña de los derechos mineros del área de interés de MCC, implicaba la intervención y el interés estatal directo en la actividad (WAGNER, 2019).

La resistencia al proyecto minero en Loncopué combinó la utilización de figuras presentes en la legislación ambiental y la legislación en materia indígena. La legislación ambiental fue clave para postergar la audiencia pública del proyecto minero, que desde 2009 venía siendo impulsada por el gobierno provincial y local sin la debida información a los pobladores de la localidad de Loncopué. Entre los principales cuestionamientos al proceso de evaluación de impacto ambiental del proyecto minero, estaba el hecho de que el estudio de impacto ambiental presentado por la empresa se encontraba en la localidad de Zapala, donde funciona la Dirección Provincial de Minería, a 124 kilómetros de Loncopué, lo que dificultaba la consulta por parte de la población local. Sumado a ello, como la audiencia estaba planificada en enero, parte de la comunidad mapuche se encontraba en la veranada. ${ }^{9}$ Estos cuestionamientos, plasmados en Recursos de Amparo, fueron retrasando la realización de la audiencia pública del proyecto, que quedó finalmente fechada para el 30 de septiembre de $2009 .{ }^{10}$ Estos recursos fueron presentados gracias al asesoramiento de un abogado que había vivido la experiencia de Esquel, quien se sumó a la asamblea de vecinos y se constituyó como abogado de la misma y de la comunidad mapuche Mellao Morales.

Paralelamente a los recursos que fueron retrasando la realización de la audiencia pública, la comunidad Mapuche Mellao Morales presentó una Medida Cautelar de “Prohibición de Innovar", con respecto a la propiedad minera (Expediente 13.595/89:

\footnotetext{
9 Esta es una actividad que las comunidades realizan con el fin de llevar a sus animales a zonas de pastos y aguadas durante el estío, se realiza en los valles de altura, excediendo en muchos casos la cota de 1.200 metros (BENDINI; TSAKOUMAGKOS; NOGUES 2004).

10 La licencia ambiental que deben obtener los proyectos, para lo cual deben presentar un estudio de impacto ambiental, sometido a audiencia pública, en Neuquén está reglamentada por la ley provincial $\mathrm{N}^{\circ}$ 1875 (de 1991, y su modificatoria, Ley N²267, de 1998).
} 
CORMINE manifestación de cobre diseminado mina Campana Mahuida). Mellao Morales fundamentó la medida en "el peligro que implica sobre los derechos comunitarios, el avance en la ejecución del contrato impugnado, ya sea consolidándose mediante inscripción de dominio minero permitiendo la posterior transferencia del contrato o la obtención de licencias de exploración o explotación minera, lo que generaría hechos irreparables al territorio de la Comunidad Mapuche" (TSJ, Resolución Interlocutoria $\mathrm{N}^{\circ}$ $6.941,2009)$. Además, se fundamentaba en la omisión de la consulta previa, aludiendo al Convenio 169 de la OIT. La medida llegó al Tribunal Superior de Justicia (TSJ) de la provincia de Neuquén, el cual dictó la "prohibición de innovar”, mediante la Resolución Interlocutoria $\mathrm{N}^{\circ} 6941$, el 28 septiembre de 2009.

Imagen1: Marcha por las calles de Loncopué, septiembre de 2009.

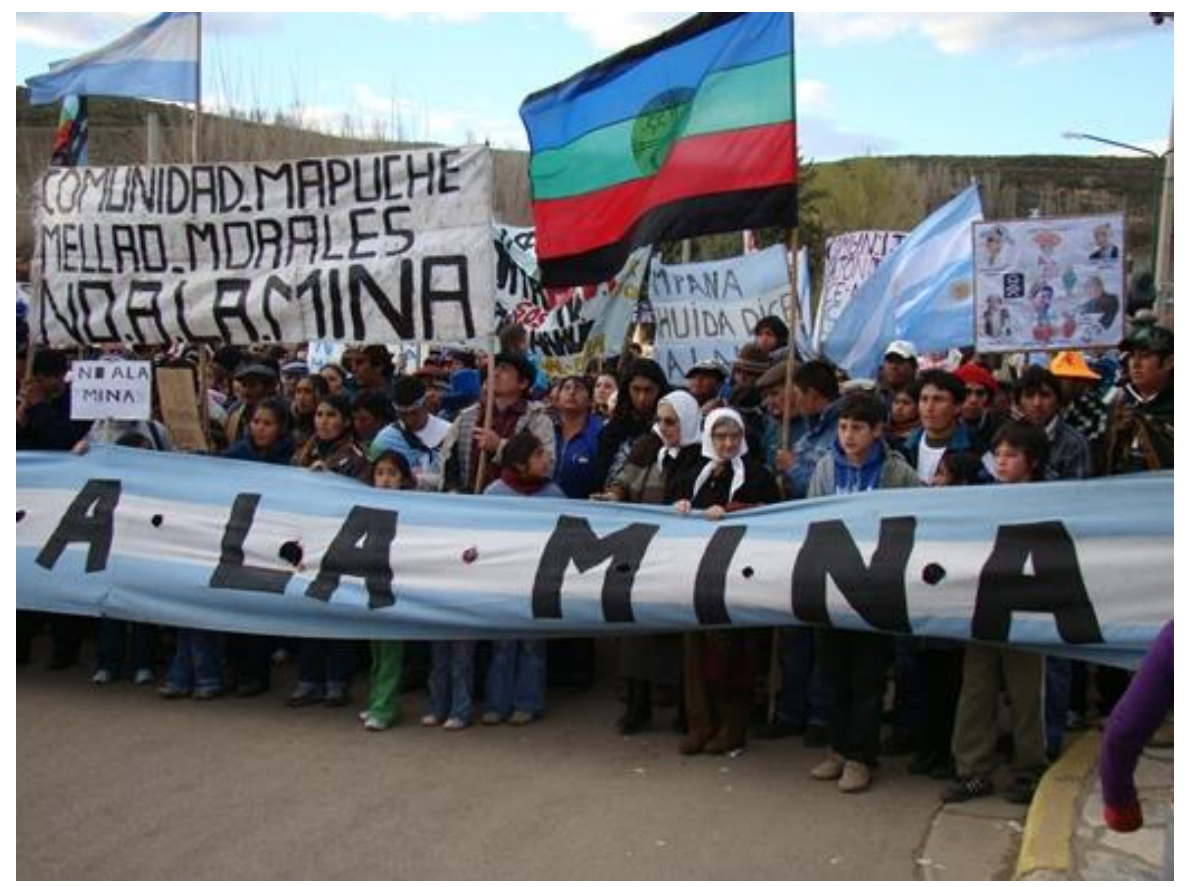

Fuente: fotografía tomada por AVAL, facilitada a Lucrecia Wagner por esta asamblea en febrero de 2016.

Así, se frenó el avance del proyecto minero, dos días antes de que se concretara la audiencia pública del mismo. La expedición del TSJ también fue impulsada por el pedido de asambleas y la comunidad mapuche, quienes, acompañadas por organismos de derechos humanos y otros movimientos sociales, solicitaron la expedición del tribunal, ante el creciente conflicto en la localidad de Loncopué. Aquí las redes también fueron un 
de la ciudad de Neuquén (WAGNER, 2019), por lo que cada una de estas acciones era acompañada desde la capital provincial.

Resulta interesante preguntarse por qué, si el proyecto fue frenado en 2009 , en 2012 se realizó una consulta comunitaria en Loncopué, para prohibir la minería a cielo abierto en la localidad. Luego de la Resolución del Tribunal, la asamblea de Loncopué siguió funcionando, y surgió la idea de presentar un proyecto de ordenanza que prohibiera la minería en la meseta municipal, a pesar de que esta meseta no incluye al Cerro Tres Puntas, lugar donde se hubiera llevado a cabo el proyecto minero. "Era una manera de poner piedritas en el camino, para hacer un cierre, hacer algo más, no pensábamos en aquel entonces en la posibilidad de un referéndum, ni lo soñábamos" (SUJETO 1, 2016, Información oral), detalla una integrante de la asamblea de Loncopué. Esta idea se concretó utilizando un procedimiento establecido en la Ley de Municipios de Neuquén, №53 (de 1958, con sucesivas modificatorias). El anteproyecto, según esta Ley, podía presentarse si recibía la adhesión de, por lo menos el 15\% de los integrantes del cuerpo electoral. Se abrió así un proceso donde la gente completó su adhesión firmando en el Juzgado, y se llegó al $24 \%$ de adhesiones. El anteproyecto fue presentado ante el Honorable Concejo Deliberante de Loncopué, que debía tratarlo dentro de los 20 días (según Ley 53), y fue rechazado. Además

la quisieron cambiar por otra, presentada por un concejal, que era igual pero en vez de meseta municipal decía casco urbano, reduciendo su alcance de 8.000 hectáreas a las calles del pueblo. Desconociendo que una ordenanza presentada por iniciativa popular se aprueba o se rechaza, no se puede cambiar por otra (SUJETO 1, 2016, Información oral).

Efectivamente, la Ley 53 establece que "En caso de pronunciamiento negativo de estos cuerpos (Honorable Concejo Deliberante), la iniciativa será sometida al referéndum popular". Agrega además que, para que sea válido el pronunciamiento popular respectivo, deben votar "por lo menos la mitad más uno de los componentes del cuerpo electoral, decidiéndose por mayoría absoluta de los votantes". Una integrante de AVAL 

expresó, ¿O no lo viste en todo este tiempo? ¿Sabés qué? Mejor que vayamos a referéndum, porque esta ordenanza la vamos a ganar, y no se la vamos a deber a ninguno de ustedes, se la vamos a deber al pueblo" (SUJETO 1, 2016, Información oral).

Allí empezó la campaña de las asambleas, puerta por puerta, explicando a la gente que para decir "No a la Mina", debían votar por "SI a la ordenanza”, realizando también programas de radio, armando jingles y spots que se escuchaban desde megáfonos de la camioneta de la parroquia, entre otras acciones. Uno de los spots más difundidos fue el que realizó el cantante Axel Fernando, quien, con el fondo de su canción Celebra la vida, relataba:

Hola vecinos de Loncopué, soy Axel, y les quiero contar que vengo siguiendo con mucha alegría su lucha contra la minería a cielo abierto, y realmente los felicito por los logros que llevan obtenidos. Ahora están frente a un momento histórico en sus vidas, y los invito a que den un paso más en defensa de la vida y el agua de todos: los invito a participar en el referéndum diciendo sí a la ordenanza que prohíbe la minería en Loncopué (Spot de la campaña por el SI, 2012).

Desde el aspecto institucional, se debió crear la Junta Comicial Municipal (JUCOM), para lo cual se eligió a cinco personas muy respetadas en Loncopué, cinco docentes jubilados (cuatro mujeres y un hombre), que serían la autoridad máxima del referéndum. Días antes, CORMINE presentó un Recurso pidiendo que se suspenda el referéndum. El gobierno provincial afirmó la inconstitucionalidad del referéndum y amenazó con presentar una causa ante el Poder Judicial planteando esta inconstitucionalidad. Además, alguien dispersó por las calles de Loncopué volantes anónimos con la consigna "No vayas a votar, no te pueden obligar". Los integrantes de las asambleas denuncian que, en las afueras de la escuela donde se realizó la votación, personas a favor del proyecto minero ofrecían dinero a la gente para que vote por el NO a la Ordenanza. Sumado a ello, se filmaba, desde la Casa de Termas ${ }^{11}$, a quienes entraban a votar, lo cual fue considerado

\footnotetext{
${ }^{11}$ La Casa de Termas de Copahue, de Loncopué, es un edificio público, municipal, donde se gestionan las termas de Copahue. Para los integrantes de AVAL constituye el edificio donde el "oficialismo" político, favorable al proyecto minero, llevó adelante sus acciones por el No a la Ordenanza, por tener una ubicación estratégica para la observación de la votación, frente a la escuela donde se realizó la misma.
} 
Por otra parte, la "mesa del NO" (quienes se oponían a la Ordenanza que prohibía la actividad minera) no se presentó en los tiempos establecidos, y vencidos los plazos, el día anterior al referéndum, quienes rechazaban la ordenanza quisieron presentar fiscales para supervisar el acto, lo cual fue negado por JUCOM al estar vencidos los plazos estipulados por ley.

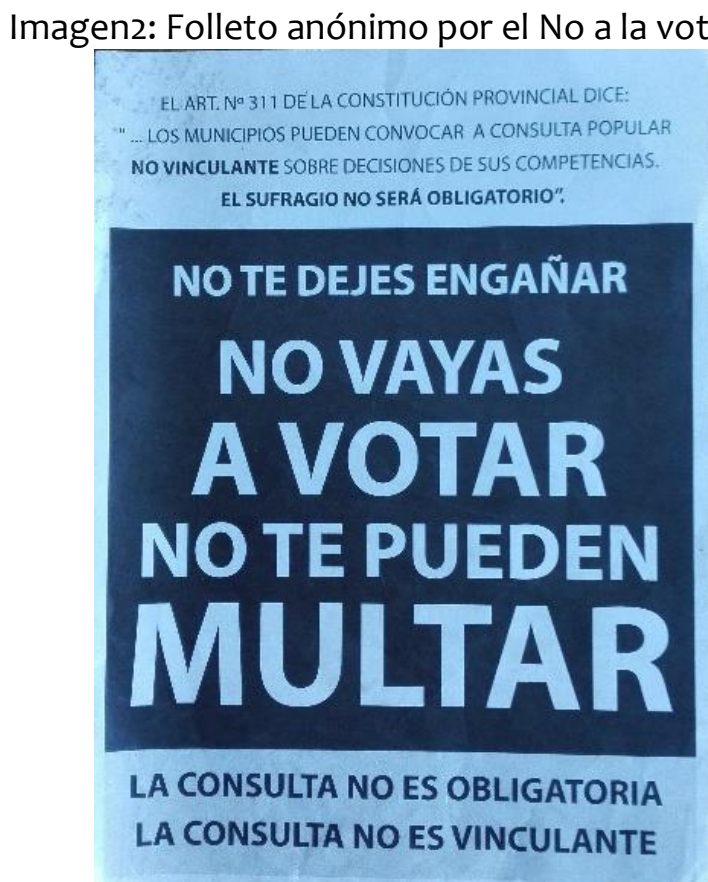

Fuente: material recopilado por AVAL, fotografiado por Lucrecia Wagner en Loncopué, febrero de 2016

El 3 de junio de 2012 se llevó a cabo el referéndum. Darío Aranda, periodista especializado en temas ambientales y de disputas territoriales, y también las Madres del Alto Valle (madres de desaparecidos en la última dictadura militar), auspiciaron de veedores. En la mañana del referéndum unas personas trabajadoras del Municipio se presentaron con una copia del padrón, marcando a la gente que ingresaba a votar. JUCOM les exigió retirarse, alertando que, si no lo hacían, llamarían a la fuerza pública. Posteriormente, ingresó el entonces Ministro de Seguridad de la provincia, argumentando que llegaba "para garantizar la transparencia de los comicios". Una de las integrantes de JUCOM le explicó: "Ministro, usted es autoridad en la provincia de 
Neuquén, pero en este ámbito, hoy, la autoridad somos nosotros, así que yo le voy a pedir que se retire" (SUJETO 2, 2016, Información oral) ${ }^{12}$. Sumado a ello, le pidió:

si usted quiere garantizar la transparencia del referéndum, vea a la gente que en la esquina le está pagando a quienes vienen a votar, para que no voten o voten por el NO a la ordenanza, vea también que en la Casa de Termas están sacando fotos y filmando, mire los panfletos ¿ésta es la transparencia que ustedes quieren? Dígale a la comisaría de Loncopué que nos proteja, exija a los que están vendiendo bebidas alcohólicas que cierren los negocios, y si quiere quedarse todo el día, quédese, y si quiere venir al recuento de votos, lo invitamos (SUJETO 2, 2006, Información oral).

A las 18 horas comenzó el recuento: votó el 73\% del padrón, y de ese porcentaje, el 83\% le dijo SI a la Ordenanza. Integrantes de AVAL denuncian que la policía había recibido órdenes de no custodiar las urnas, y jóvenes del pueblo se ofrecieron a custodiarlas toda la noche. La presencia mediática hizo cambiar las órdenes, y finalmente la policía custodió las urnas.

Imagen3: Festejo por las calles de Loncopué, posterior al conteo de votos del referéndum

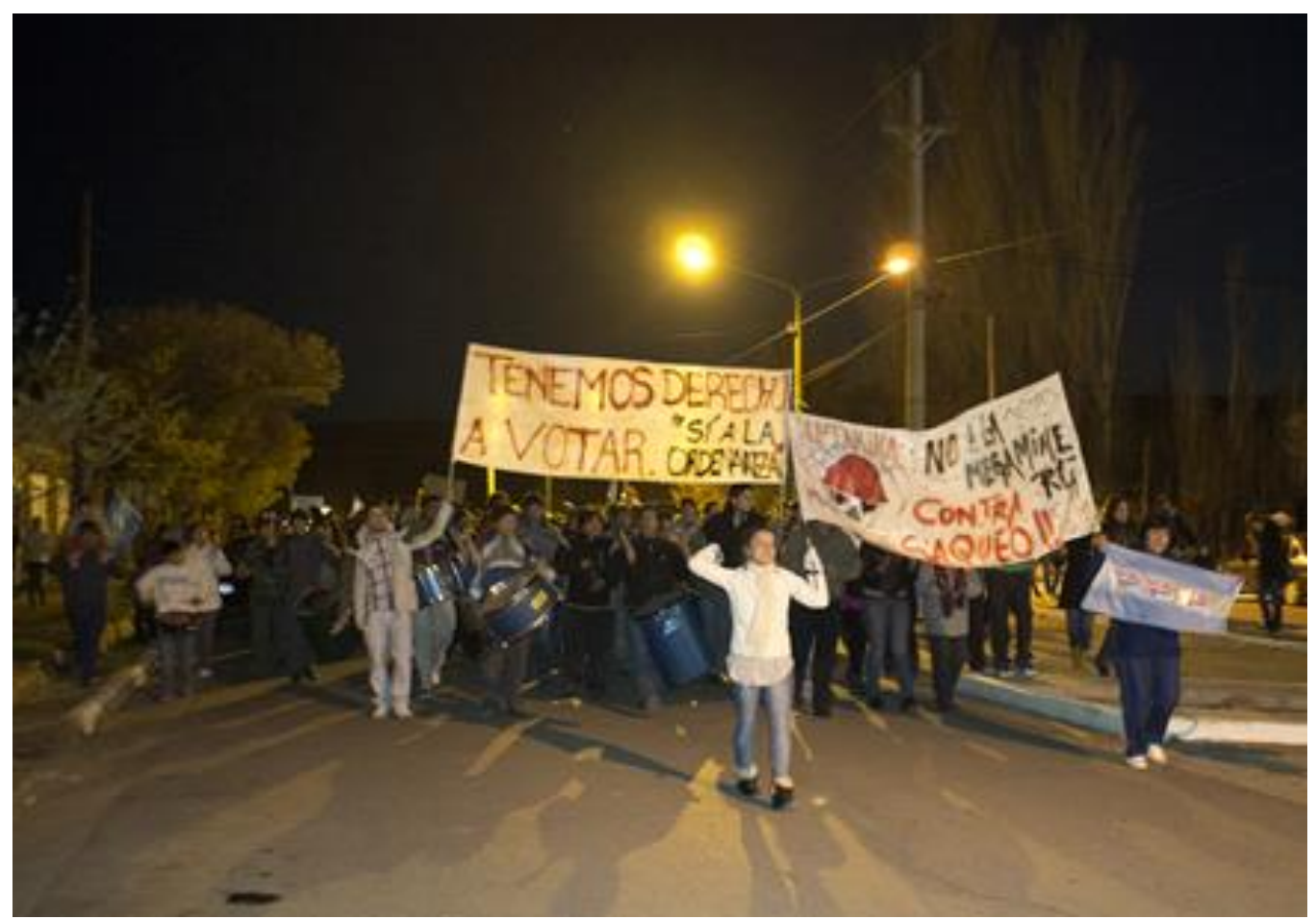

Fuente: fotografía tomada por AVAL, facilitada a Lucrecia Wagner por esta asamblea, en febrero de 2016.

12 Fuente: entrevistas a integrante de la Asamblea de vecinos de Loncopué. Loncopué, Neuquén, septiembre de 2016. 
Posteriormente, el Fiscal de Estado presentó un Recurso de Inconstitucionalidad, que luego retiró (LA PROVINCIA, 2012). El tratamiento mediático del tema varió según los medios de prensa, como analiza Isabel Salerno:

La información presentada los días 3 y 4 de Junio muestran que, mientras La mañana del Neuquén se limita a poner en el centro de la información las acciones y los dichos del gobierno provincial en su intento por desalentar la participación ciudadana y deslegitimar el acto comicial, Río Negro centra la atención en el referéndum como acción legítima, en la participación ciudadana y en los obstáculos interpuestos por el gobierno neuquino (SALERNO, 2013, p. 2). ${ }^{13}$

Imagen 4: Mural pintado luego del referéndum en la pared de la Parroquia de Loncopué.

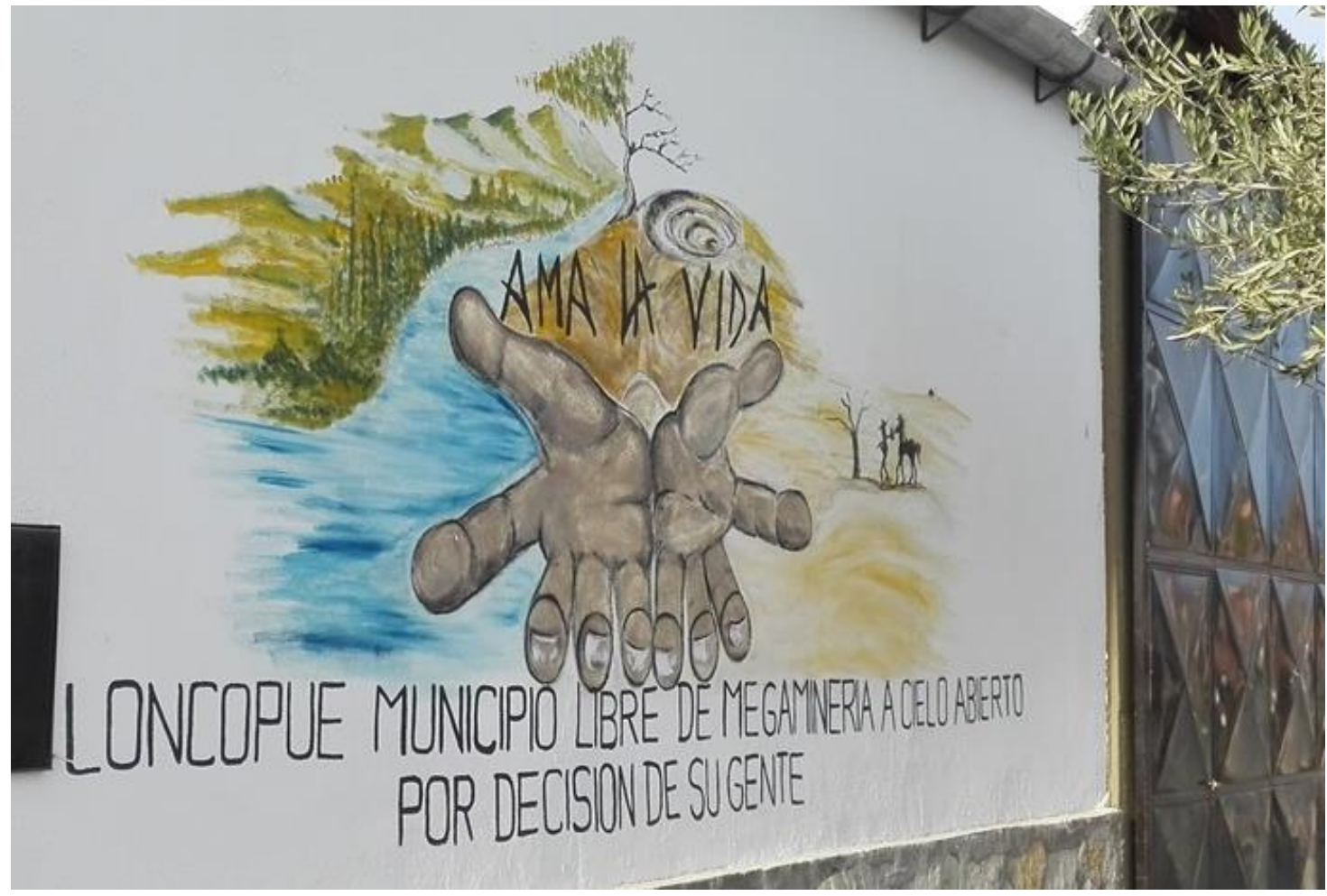

Fuentes: Mural pintado en una de las paredes de la iglesia local. Fotografía tomada por Lucrecia Wagner durante el trabajo de campo. Loncopué, febrero de 2016.

13 Principales medios de prensa escritos de la región, en línea: https://www.Imneuquen.com/ y https://www.rionegro.com.ar/ 
Cuadro 1. Características de las consultas comunitarias en Argentina.

\begin{tabular}{|c|c|c|c|c|c|}
\hline LUGAR & AÑO & ALCANCE & $\begin{array}{c}\text { FORMA DE LA } \\
\text { CONSULTA }\end{array}$ & $\begin{array}{c}\text { PROYECTO } \\
\text { VOTADO }\end{array}$ & $\begin{array}{c}\text { VOTOS POR EL } \\
\text { NO AL } \\
\text { PROYECTO (\%) }\end{array}$ \\
\hline Misiones & 1996 & Provincial & $\begin{array}{c}\text { Plebiscito } \\
\text { obligatorio y } \\
\text { vinculante }\end{array}$ & $\begin{array}{c}\text { Hidroeléctrico: } \\
\text { Corpus Christi }\end{array}$ & 88,63 \\
\hline $\begin{array}{c}\text { Esquel } \\
\text { (Chubut) }\end{array}$ & 2003 & Local & $\begin{array}{c}\text { Plebiscito No } \\
\text { vinculante }\end{array}$ & $\begin{array}{c}\text { Minero. Cordón } \\
\text { Esquel }\end{array}$ & 81 \\
\hline $\begin{array}{c}\text { Loncopué } \\
\text { (Neuquén) }\end{array}$ & 2012 & Local & $\begin{array}{c}\text { Referéndum } \\
\text { vinculante }\end{array}$ & $\begin{array}{c}\text { Minero. Campana } \\
\text { Mahuida }\end{array}$ & 83 \\
\hline Misiones & 2014 & Provincial & $\begin{array}{c}\text { Consulta No } \\
\text { vinculante }\end{array}$ & $\begin{array}{c}\text { Complejo } \\
\text { Hidroeléctrico } \\
\text { Garabí-Panambí }\end{array}$ & 96 \\
\hline
\end{tabular}

Fuente: elaboración propia en base a fuentes documentales.

\section{Reflexiones finales}

Las consultas realizadas en Argentina derivadas de conflictos ambientales han surgido, como puede observarse en los casos descritos, gracias a las demandas de la población afectada. Surgen de procesos cortos de formación e información, como Esquel, o de periodos más largos con proyectos previamente suspendidos, como Loncopué. Tienen escala local en el caso minero, y provincial en el caso de las represas en Misiones. Pero más allá de estas diferencias, todas sorprendieron a los poderes políticos y a los gobiernos locales y provinciales, porque representaron un momento donde la población le puso un freno a la delegación de su voto, pasando de ser representados a ser partícipes de la gestión del espacio participativo. Emergieron en momentos de profunda crisis socioeconómica y política, como Esquel, o sucedieron en poblaciones, como Loncopué, donde la mayor parte de la población depende del empleo estatal y vota por el partido oficial, al cual le dio la espalda puntualmente en relación al proyecto minero. En el caso de las represas, la población misionera se expuso a ser foco de críticas a nivel nacional, por “negar" la posibilidad de obtener energía hidroeléctrica para Argentina, y/o para otros países (por tratarse de proyectos binacionales). En Misiones se observa además cómo, aun teniendo legislación que debería garantizar la votación, al incumplirse la misma las organizaciones toman el rol de impulsar la realización de consultas, de manera autogestiva. 
Por lo expuesto, puede concluirse que las autoridades ejecutivas y legislativas del Estado no han velado en estos conflictos por el cumplimiento de la legislación existente, y ante ello, han sido las comunidades locales las que recurrieron a la normativa existente para respaldar su derecho a ser parte del proceso de toma de decisiones que afectarían su lugar de vida. Es decir, la necesidad de las comunidades de hacer escuchar su voz respecto a la instalación de proyectos extractivos, se combinó con un aprendizaje colectivo respecto a las normas y procedimientos ambientales, lo cual derivó en la puesta en práctica de mecanismos participativos existentes, que son impulsados y organizados por las poblaciones locales, cuando deberían haber sido garantizados por las autoridades estatales.

El caso de Loncopué cuenta además con el aditivo de la participación de especialistas del derecho con experiencia previa en el conflicto de Esquel, lo cual constituye una "transmisión del acervo vivencial" que se vuelve clave y se pone en juego al recurrir a la vía judicial. Además, la comunidad de Loncopué al hacer uso de la normativa existente creó condiciones institucionales para el despliegue del referéndum, por ejemplo, dándole cuerpo y forma a la JUCOM, es decir, materializando lo establecido por la legislación existente.

Los movimientos socioambientales que llevaron adelante estas experiencias fueron capaces también de condensar expectativas de diversos sectores de sus poblaciones, y parte de su éxito se funda en la capacidad de superar el debate político partidario, gracias a la heterogeneidad de sus integrantes y de perspectivas de vida que confluyen en ellos. Además, tuvieron la fuerza de desplegar acciones creativas y convocantes, que despertaron en sus vecinos la iniciativa de participar, una capacidad que cuando se despierta, moviliza fuerzas y normas que habían permanecido mucho tiempo dormidas, desplegando impulsos latentes que permiten alcanzar lo que antes parecía imposible. 


\section{Referencias}

ABERS, Rebecca; GUTIÉRREZ, Ricardo; ISUANI, Fernando; VON BÜLOW, Marisa. La construcción de instituciones ambientales en Argentina, Brasil y Chile. In: CONGRESO NACIONAL DE CIENCIA POLÍTICA, XI, 2013. Paraná: Sociedad Argentina de Análisis Político. Panel: Instituciones y actores en la implementación de políticas ambientales. Disponible en: http://www.unsam.edu.ar/profesores/ricardogutierrez/SAAP\%202013_ Abers,\%20Guti\%C3\%Agrrez,\%20lsuani\%20\&\%20Von\%20B\%C3\%BClow_ponencia.pdf. Acceso en: 14 octubre 2019.

ALIMONDA, Héctor (coord.). La naturaleza colonizada: ecología política y minería en América Latina. Buenos Aires: CLACSO-Ciccus, 2011.

ALIMONDA, Héctor. Los tormentos de la materia: aportes para una ecología política latinoamericana. Buenos Aires: CLACSO, 2006.

ANDERSON, Benedict. Comunidades imaginadas: reflexiones sobre el origen y la difusión del nacionalismo. México: Fondo de Cultura Económica, 1993.

ARANDA, Dario. Urnas por el rechazo. Página 12, Buenos Aires, 23 de octubre de 2014. Disponible en: https://www.pagina12.com.ar/diario/sociedad/3-258141-2014-10-23.html. Acceso en: 14 octubre 2019.

ARGENTINA. Ley n ${ }^{\circ}$ 25.432, de 23 de mayo de 2001. Establece las disposiciones de la Consulta Popular Vinculante y No Vinculante. Argentina: Ministerio de Justicia y Derechos Humanos, Presidencia de la Nación. Disponible en: http://servicios.infoleg.gob.ar/ infolegInternet/anexos/65000-69999/67518/norma.htm. Acceso en: 14 octubre 2019.

ARGENTINA. Ley ${ }^{\circ}$ 26.774, de 31 de octubre de 2012. Ley de Ciudadanía Argentina. Modifíca las Leyes $n^{\circ} 346,17.671,19.945,23.298,25.432,26.215$ y 26.571. Argentina: Ministerio de Justicia y Derechos Humanos, Presidencia de la Nación. Disponible en: http://servicios.infoleg.gob.ar/infolegInternet/anexos/200000-204999/204176/norma.htm. Acceso en: 14 octubre 2019.

BEBBINGTON, Anthony. Social conflict, economic development and extractive industry: evidence from South America. London: Routledge, 2012.

BENDINI, Mónica; TSAKOUMAGKOS, Pedro; NOGUES, Carlos. Los crianceros trashumantes en Neuquén. In: BENDINI, Mónica; ALEMANY, Carlos (comp.). Crianceros y chacareros en la Patagonia. Buenos Aires: Editorial La Colmena, 2004. p. 23-40. 
BENÍTEZ, Silvia, HERTTER, Daniela. ONG's ambientalistas en la provincia de Misiones: prácticas políticas, organizativas e institucionales en relación con la construcción de obras hidroeléctricas. In: JORNADAS DE SOCIOLOGÍA, VII, 2012, La Plata. Memoria Académica, Universidad Nacional de La Plata, 5-7 diciembre 2012, La Plata. Disponible en: http://www.memoria.fahce.unlp.edu.ar/trab_eventos/ev.1718/ev.1718.pdf. Acceso en: 14 octubre 2019.

CHIAPPE, Lucas (coord.). La Patagonia de Pie: ecología vs. negociados. Chubut: Proyecto Lemu-Grupo de Amigos del Libro, 2005.

CHRISTEL, Lucas; GUTIÉRREZ, Ricardo. Making rights come alive: environmental rights and modes of participation in Argentina. Journal of Environment \& Development, Newbury Park v. 26, n. 3, p. 322-347, 2017.

CLAPS, Luis; COLAO, Diego. Comunicación, recursos naturales y comunidad en el caso Esquel. 2005. Tesina (Licenciatura en Ciencias de la Comunicación) - Facultad de Ciencias Sociales, Universidad de Buenos Aires, Buenos Aires, 2005.

DELAMATA, Gabriela. Actualizando el derecho al ambiente: movilización social, activismo legal y derecho constitucional al ambiente de «sustentabilidad fuerte» en el sector extractivista megaminero. Entramados y perspectivas, Buenos Aires, v. 3, n. 3, p. 55-90, 2013 .

DI PAOLA María Eugenia; NÁPOLI, Andrés. El ambiente y las instituciones en la República Argentina. In: Centro de Estudios Legales y Sociales (CELS). Derechos humanos en la Argentina. Buenos Aires: Siglo XXI Editores, 2007, p. 465-472.

DIETZ, Kristina. Consultas populares mineras en Colombia: condiciones de su realización y significados políticos: el caso de La Colosa. Colombia Internacional, Bogotá, n. 93, p. 93117, enero/marzo 2018.

GÓMEZ, Anahí; WAGNER, Lucrecia, TORRES, Beatriz, MARTÍN, Facundo; ROJAS, Facundo. Resistencias sociales en contra de los megaproyectos hídricos en América Latina.

European Review of Latin American and Caribbean Studies, Amsterdam, n. 97, p. 81-104, oct. 2014.

GUAJARDO, Carlos. Marcha contra la instalación de una mina de oro en Esquel. Clarín, Buenos Aires, 5 dic. 2002. Disponible en: https://www.clarin.com/sociedad/marchainstalacion-mina-oro-esquel_o_H1w-TfQxote.html. Acceso en: 14 octubre 2019.

GUTIÉRREZ, Ricardo. Teoría y praxis de los derechos ambientales en Argentina. Temas y debates, Rosario, n. 30, año 19, p. 13-36, jul./dic. 2015. 
HINCAPIÉ, Sandra. Entre el extractivismo y la defensa de la democracia. Mecanismos de democracia directa en conflictos socioambientales de América Latina. Recerca, Castelló de la Plana, n. 21, p. 37-61, 2017.

HOGENBOOM, Bárbara; BAUD, Michiel; DE CASTRO, Fabio (coords.). Gobernanza ambiental en América Latina. Buenos Aires: CLACSO, 2015.

INDEC (INSTITUTO NACIONAL DE ESTADÍSTICA Y CENSOS). Censo Nacional de Población: hogares y viviendas. Argentina: [s.n.], 2010.

KLEIN, Naomi. Once Strip-Mined, Twice Shy, Naomi Klein, 23 de septiembre de 2003. Disponible en: https://naomiklein.org/once-strip-mined-twice-shy/. Acceso en: 14 octubre 2019.

LA PROVINCIA irá al TSJ por el referéndum en Loncopué. Río Negro, General Roca, 4 jun. 2012. Disponible en: https://www.rionegro.com.ar/la-provincia-ira-al-tsj-por-el-referendumen-loncopue-HQRN_890236/. Acceso en: 14 octubre 2019.

MARTÍNEZ ALIER, Joan. El ecologismo de los pobres: conflictos ambientales y lenguajes de valoración. Barcelona: Icaria Antrazyt-FLACSO, 2004.

MARTÍNEZ ALIER, Joan; TEMPER, Leah; DEL BENE, Daniela; SCHEIDEL, Arnim. Is there a global environmental justice movement? The Journal of Peasant Studies, London, v. 43, n. 3, p. 731-755, 2016.

MELÉ, Patrice. Identifier un régime de territorialité reflexive. Coloquio Territoires, territorialité, territorialisation: et après? Grenoble; Université Joseph Fourier; UMR Pacte Territoire; CNRS; Francia, 7-8 jun. 2007.

MERLINSKY, Gabriela (comp.) Cartografías del conflicto ambiental en Argentina. Buenos Aires: CLACSO-CICCUS, 2013.

MISIONES, Ley IV - $\mathrm{n}^{\circ}$ 56, de 20 de octubre de 2011. Declara la plenitud del dominio imprescriptible e inalienable de la Provincia sobre sus recursos naturales hídricos. Establece el proceso decisional del Patrimonio Natural de los misioneros. Instituye una nueva coparticipación económica para Misiones: la Soberanía Energética. Misiones, http://digestomisiones.gob.ar/uploads/documentos/leyes/LEY\%20IV\%20-\%20N\%2056.pdf Acceso en: 14 octubre 2019.

MISIONES, Ley $n^{\circ}$ 3294, de 20 de junio de 1996. Ratifica y Otorga Carácter de Ley a la Resolución $N^{\circ} 420 / 96$ del Tribunal Electoral referida al Plebiscito sobre el Emprendimiento Hidroeléctrico de Corpus. Actual Ley XI - N 5 . Misiones, Cámara de Representantes. Disponible en: http://digestomisiones.gob.ar/uploads/documentos/leyes/LEY\%20XI\%20\%20N\%205.pdf. Acceso en: 14 octubre 2019. 
MISIONES, Ley n 3220, de 1995. Régimen de consulta popular "Corpus Christi", Subdirección de Información Parlamentaria, Secretaría Legislativa, Cámara de Representantes, Misiones.

MOORE, Leslie. A town's protests threaten Argentina's mining future. New York Times, New York, 20 abr. 2003. Section 3, Page 6, Business. Disponible en: https://www.nytimes.com/2003/04/20/business/business-a-town-s-protests-threatenargentina-s-mining-future.html. Acceso en: 14 octubre 2019.

NOEVER, Carla; DIETZ, Kristina. Popular consultations concerning mining in Latin America. In: GLOCON (Global Change-Local Conflicts). Berlín, 2017. Disponible en: https://www.land-conflicts.fu-berlin.de/en/multimedia/overview-consultas/index.html. Acceso en: 14 octubre 2019.

Tribunal Superior de Justicia (TSJ), Neuquén. Secretaría de Demandas Originarias. Resolución Interlocutoria N 6.941, 28 de sept. 2009. [Autos caratulados "Comunidad Mapuche Mellao Morales C/Corporación Minera del Neuquén S.E s/Acción Procesal Administrativa"]. Expediente n ${ }^{\circ}$ 2642/9. Disponible en: http://200.41.231.85/PrensaWeb.nsf/9dc53977874bdfbd032575a5004f6fo2/2f9665771ba5d 48d0325763foo6oe718?OpenDocument. Acceso en: 14 octubre 2019.

SALERNO, Isabel. Referéndum contra la megaminería en Loncopué. La producción discursiva de los diarios La Mañana de Neuquén y Río Negro. In: ENCUENTRO PANAMERICANO DE COMUNICACIÓN (COMPANAM), VI, 2013, Córdoba. COMPANAM 2013. Eje temático: Producción discursiva y medios de comunicación, p. 1-15. Disponible en:

http://www.publicacioncompanam2013.eci.unc.edu.ar/files/companam/ponencias/Produc ci\%C3\%B3n\%20discursiva/-Unlicensed-Producci\%C3\%B3n-discursiva-y-medios-decomunicaci\%C3\%B3n.-Salerno.pdf. Acceso en: 14 octubre 2019.

SCHIAFFINI, Hernán. El agua vale más que el oro: la constitución de fuerzas sociales en torno al conflicto minero en Esquel. 2002-2003. 2003. Tesis (Licenciatura del Departamento de Ciencias Antropológicas) - Facultad de Filosofía y Letras, Universidad de Buenos Aires, Buenos Aires, 2003.

SPOT DELA CAMPAÑA POR EL SÍ, 2012. [Grabación cedida por AVAL a] Lucrecia Wagner, Loncopué, Neuquén, septiembre de 2016.

SUJEITO 1. [Entrevista cedida a] Lucrecia Wagner, Loncopué, Neuquén, 20 de septiembre de 2016.

SUJEITO 2. [Entrevista cedida a] Lucrecia Wagner, Loncopué, Neuquén, 25 de febrero de 2016. 
SVAMPA, Maristella. Debates latinoamericanos: indianismo, desarrollo, dependencia y populismo. Buenos Aires: Edhasa, 2016.

WAGNER, Lucrecia. Propuestas de inversiones chinas en territorio mapuche: resistencias a la minería metalífera en Loncopué. Estudios Atacameños, San Pedro de Atacama, 2019 (en prensa).

WALTER, Mariana; URKIDI, Leire. 2015. Consultas comunitarias y vecinales contra la minería metalífera en América Latina (2002-2012). Ecología Política, Barcelona, n. 48, p. 48-53, 2015.

WALTER, Mariana. Nuevos conflictos ambientales mineros en Argentina. El caso Esquel (2002-2003). Revista Iberoamericana de Economía Ecológica, Rio de Janeiro, n. 8, p. 15$28,2008$.

WALTER, Mariana. Political ecology of mining conflicts in Latin America: an analisys of environmental justice movements and struggles over scales. 2014 Tesis (Doctorado en el Programa en Ciencias Ambientales) - Instituto de Ciencia y Tecnologías Ambientales, Universidad Autónoma de Barcelona, Barcelona, 2014.

WEINSTOCK, Ana Mariel. "Si a la vida; no a la mina": Voces y acciones confrontando el modelo de desarrollo en Patagonia. Alemania: Editorial Académica Española, 2012.

Recebido em 25/02/2019 Aprovado em 13/08/2019

Universidade do Estado de Santa Catarina - UDESC Programa de Pós-Graduação em História - PPGH

Revista Tempo e Argumento Volume 11 - Número 28 - Ano 2019 tempoeargumento@gmail.com 